\title{
Association Between Occupation Type and Obesity Prevalence: An Analysis of the 2018 Korea National Health and Nutrition Examination Survey
}

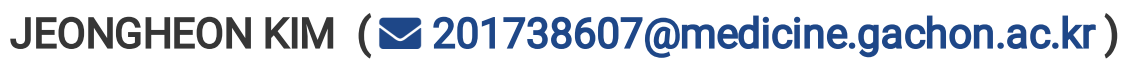

Gachon University of Medicine and Science: Gachon University

Kyu Rae rae Lee

Gachon University of Medicine and Science: Gachon University https://orcid.org/0000-0003-2178-0459

\section{Research Article}

Keywords: obesity prevalence, occupation, BMI, waist circumference Level of evidence, Level III: Evidence obtained from well-designed cohort or case-control analytic studies

Posted Date: March 5th, 2021

DOl: https://doi.org/10.21203/rs.3.rs-233561/v1

License: (c) (i) This work is licensed under a Creative Commons Attribution 4.0 International License.

Read Full License 


\section{Abstract}

Purpose : Although occupational factors such as working hours, type of workers, and being a shift worker have been associated with the prevalence of obesity, the relationships between occupation type and obesity prevalence, especially in South Korea, have not been clarified. We therefore investigated the association between obesity markers such as body mass index (BMI) and waist circumference (WC) and types of occupation using data from the 2018 Korea National Health and Nutrition Examination Survey. Methods: We evaluated the height, weight, WC, -and demographic variables (age, sex, socioeconomic status, alcohol, and smoking) from data of 3,645 respondents. The occupational groups were classified into nine categories (managers, professionals and related workers, clerks, service workers, sales workers, skilled agriculture, forestry and fishery workers, craft and related trade workers, equipment, machine operating and assembling workers, and elementary workers) using the Korean version of the Standard Classification of Occupations. We performed an analysis of covariance test to assess the relationship between obesity markers (BMl; and WC) and types of occupation. Results: There was a significant difference in obesity markers among men according to occupation categories after controlling for sociodemographic covariates. The prevalence of obesity was significantly higher in managers $(25.8+/-0.4$ $\mathrm{kg} / \mathrm{m} 2,89.7+/-1.1 \mathrm{~cm})$, and lower in craft and related trade workers $(24.3+/-0.2 \mathrm{~kg} / \mathrm{m} \mathrm{2}, 85.1+/-0.6$ $\mathrm{cm})$, respectively . $(p=0.011)$. Conclusion: The obesity markers were highest in the manager group and lowest in the craft and related trades workers group among men of all the occupation groups.

\section{Introduction}

Overweight and obesity has been defined as the abnormal or excessive fat accumulation that presents a risk to health. [1] A prospective study has shown that a healthy BMI (Body Mass Index) and WC (Waist Circumference) are important indicators of obesity among patients with diabetes. [2] According to the Korean Society for the Study of Obesity (KSSO) guidelines, Class I obesity is defined as a BMI $25 \mathrm{~kg} / \mathrm{m} 2<$ $30 \mathrm{~kg} / \mathrm{m} 2$ in Korea. [3] In addition, the cut-off values for WC to predict metabolic risk factors in Koreans, were $85 \mathrm{~cm}$ in men and $80 \mathrm{~cm}$ in women. [4]

According to data from the Korea CDC, the prevalence of obesity increased from $34.7 \%$ in 2005 to $42.8 \%$ in 2018. [5] Obesity was considered to be a risk factor for the metabolic syndrome, type 2 diabetes mellitus (T2DM), hypertension, coronary artery disease, stroke, respiratory effects, types of cancers [6] and other associated factors including genetic [7], social [8], environmental factors [9]. Occupational factors that were related to obesity were identified as working hours [10,11], type of work [12,13], and being a shift worker. $[14,15]$ In particular, for the factor, type of work, the prevalence of obesity was higher in health care support, protective service, transportation, and material moving workers in the US [12], and the BMI was higher in male intermediate transport and production workers than in unemployed individuals in Australia. [13] In addition, from 1998 to 2015, the prevalence of obesity showed an increase for manual male workers (31.1 to $39.5 \%)$, service/sales workers (32.3\% to $38.2 \%)$, and non-manual workers $(25.3 \%-39.7 \%)$ in Korea. [16] Working conditions such as longer sedentary working and more 
frequent eating out were shown to demonstrate higher health risks such as the metabolic syndrome. [17, 18]

However, the relationships between the types of occupation and the prevalence of obesity have not been clarified in Korea. Therefore, we aimed to investigate the association between obesity markers such as BMI and WC and types of occupation using the 2018 Korea National Health and Nutrition Examination Survey (KNHANES) data.

\section{Method}

Participant and database information

To periodically assess nutrition, health behavior, and food consumption status, the K-CDC (Korea Center for Disease Control) conducted the KNHANES (version 7, n=7,992) in 2018. We investigated 3,645 respondents excluding the non-applicants, those who were in military service, and the non-answerers among them. The Institutional Review Board (IRB) of the Korean Centers for Disease Control and Prevention approved our study (IRB: 2013-12EXP-03-5C).

Measures

Body Mass Index and Waist Circumference

BMI ( $\mathrm{kg} / \mathrm{m} 2)$ was expressed as body weight $(\mathrm{kg})$ divided by height (meter square) and the WC (Waist circumference, $\mathrm{cm}$ ) was measured at the midpoint between the lower borders of rib cage and the anterior superior iliac spine along the mid-axillary line. [19]

Occupation

We classified the types of occupation into nine major categories based on the Korean standard classification of occupations: managers, professionals and related workers, clerks, service workers, sales workers, skilled agriculture, forestry and fishery workers, craft and related trade workers, equipment, machine operating and assembling workers, and elementary workers.

Statistical analysis

We assessed the association between types of work and the obesity markers, BMI and WC, after adjusting for age, sex, economic status, education, smoking, and alcohol consumption. A P-value less than 0.05 was considered significant. We performed an analysis of covariance test to assess the relationship between types of work and the BMI and WC using the post hoc Bonferroni method. SPSS 18.0 software (IBM Corp., NY, USA) was used for the statistical analyses.

\section{Results}


We investigated 3,645of the 7,992 participants, whose characteristics are described in Table 1.

The differences in the BMI and WC related to occupation are described in Table 2). For males, the mean BMI was $24.8 \pm 3.3$ and the mean WC $87.0 \pm 9$.7. There were statistically significant differences in both the $\mathrm{BMI}$ and WC according to occupation category ( $\mathrm{p}$-value $=.002, .001)$. The mean BMI and WC of the managers were $25.7 \pm 2.6$ and $90.0 \pm 7.2$, respectively, with managers having the highest BMI and WC. Elementary workers had the lowest BMI $(24.2 \pm 3.3)$ with craft and related trade workers having the lowest WC (85.2 \pm 8.4$)$.

For females, the mean BMI was $23.3 \pm 3.8$, and the mean WC $77.8 \pm 9.4$. There were also statistically significant differences in both the BMI and WC according to occupation category ( $p$-value $=.002, .001$ ). The mean BMI of managers $(21.9 \pm 2.5)$ and the mean WC of clerks $(74.6 \pm 8.9)$ were the lowest. Skilled agricultural, forestry, and fishery workers had the highest BMI (25.0 \pm 3.7$)$ and WC $(82.4 \pm 10.1)$.

From the correlation analysis between the obesity markers BMI and WC and occupation after controlling for the covariates (age, education, income, and alcohol, smoking), the obesity markers were significantly different according to occupation categories in male subjects $(p=.042, .002$, Table 3$)$.

The BMI and WC (Mean \pm S.D.) estimates were based on the occupational categories using post hoc analysis. (Figure 1, Figure 2). We found that there was a significant difference between the managers whose WC was the highest and craft and related trade workers whose WC was the lowest $(p=0.011)$. However, no difference was found among occupation categories for BMI according to the Bonferroni method.

\section{Discussion}

The obesity markers such as $\mathrm{BMI}$ and WC of male managers were the highest among the occupation groups, while that of male craft and related trades workers were the lowest. The results for the male managers were consistent with the 2019 KSSO obesity fact sheet. However, while the WC in craft and related trades workers was the lowest in the present study, according to the 2019 KSSO fact sheet, it was the 2 nd highest among occupation groups. We therefore inferred that smoking and alcohol consumption could have been the confounding factor, that led to the inconsistency between the present study and the KSSO results. We found that the ratio of "smoking everyday" was higher $(46.1 \%)$ in craft and related traded workers than in other occupation groups and that of "alcohol consumption more than 3 times a week" was also higher (48.3\%).

The findings of a study conducted in a Japanese metal-product producing factory, indicated that obesity markers such as the BMI and Waist to hip ratio (adjusted for age) of managers was the highest among the male occupation groups. [20] In a study using data from the China Health and Nutrition Survey, obesity rate (BMI>25) was found to be the highest in the low-intensity workload group. [21] High socioeconomic status was also found to be one of the significant risk indicators for general and central 
obesity in Bangladesh. [22] The results of the present study produced were similar to those of other Asian studies.

An Australian health survey found that while the intermediate production and transport occupation group had the highest risk of $\mathrm{BMI} \geq 25 \mathrm{~kg} / \mathrm{m} 2$ in men, professionals showed no increase in the likelihood of being overweight and managers had a decreased risk after adjustment for socioeconomic factors. [13] A 2014 US worker-based study found that while the BMI of managers was lower, those of health care support, protective service, and transportation and material moving occupation were higher. [12] The prevalence of obesity in health and social assistance and public administration industries, whose employment was more than 40 hours a week and where there was exposure to a hostile environment, was higher than found in other US studies [23] A Finnish study showed that the prevalence of obesity in managers was not different from that in other occupation groups in men, but was lower than that in other occupation groups in women, [24] while the BMI $(24.9 \mathrm{~kg} / \mathrm{m} 2)$ of managers, workers in trade industries, and transportation occupations of were highest in the Netherlands. [25]

It should be noted that previous studies $[20,21,22]$ have reported that the prevalence of obesity in the manager group was somewhat higher in Asian studies than in Western studies. These findings were most likely to be related to differences between Asian and Western cultural lifestyles because studies have also found that the prevalence of obesity was closely associated with social lifestyle. $[17,18,26]$ Several East Asian countries have a common unique cultural background ("Confucianism"), which represents paternalistic and male domineering characteristics. Korea is one of the countries most influenced by this background and most Koreans follow the duties and responsibilities required in hierarchical society in Korea. [27]

Confucianism is based on human relationships, which focuses on a deference to authority based on hierarchical social relationships. [28] In addition, the family is considered as a prototype of social institutions. In Confucianism, the elderly and men have more respectable positions than the young and women among family members. [28] Taken together, the family context is applied to that of a company. Persons in the manager group are considered as the father, a high position in the family, while those of the rest of the occupational groups as young sibling or woman. [29] Therefore, it can be inferred that managers in high positions make policies, create orders, and workers in low positions follow orders unconditionally, which means that managers often have a tendency to have low occupational physical activity. 64 out of 66 answered "no" to the questionnaire "how hard do you do over moderate intensity physical activities with work?" in the present study.

Previous studies have reported that people with low occupational physical activity are more obese than others. $[30,31]$ In addition, according to the British Registrar Classification this group consumed more fried foods, table sugar, potatoes, and less vegetables and fish than the high occupational group. [32] In the present study found that the higher the frequency of eating out, the higher the energy intake, especially the high fat intake. [33] The proportion of male managers with a high income was higher than that of others $(60.6 \%)$, and the frequency of eating out (5 times per week) was also higher $(77.6 \%)$. 


\section{Strength And Limits}

In the present study, specific occupation (male manager) of Korea which has higher risk of obesity is directly presented and it is unusual result compared to previous studies about association between obesity prevalence and occupation category in western countries. But the present study had several limitations. First, the present data was obtained from a cross-sectional cohort consisting of socioeconomic variables and 3,645 participants; hence, a longer and larger cohort study is needed in order to reflect the whole population. Second, we did not study important confounder covariates such as physical activity and energy intake in obesity. According to the Hispanic Community Health Study, the prevalence of obesity in managers is relatively lower because they have a higher level activities such as leisure, outside of the work environment. [34] Third, there was a sampling bias due to the low number in the female manager group $(n=7)$ in the present data; therefore, we could not obtain a significant outcome between sex and occupation.

"What is already known on this subject?"

In previous studies, relationship between obesity prevalence and occupation type had been studied mostly in western countries and results showed that manager group had low obesity prevalence. We believe that our study makes a significant contribution to the literature because the relationships between the types of occupation and the prevalence of obesity have not been clarified in Korea.

"What this study adds?"

This study adds that in South Korea, one of the east Asian country, male manager group has higher prevalence of obesity than other occupation groups.

\section{Conclusion}

In conclusion the prevalence of obesity markers such as BMI and WC in the male manager group was the highest among all categories of occupations, while in the male craft and related trades workers group it was the lowest. Although our results need to be confirmed by further studies, they suggest that people of the manager group should carefully look at their obesity markers (BMI and WC). Further, a longer and larger controlled cohort study should be considered in the future.

\section{Declarations}

Due to technical limitations, Declarations section is not available for this version.

\section{References}

[1] Hruby A, Hu FB. The Epidemiology of Obesity: A Big Picture. Pharmacoeconomics. 2015;33(7):673689. doi:10.1007/s40273-014-0243-x 
[2] Katzmarzyk PT, Hu G, Cefalu WT, Mire E, Bouchard C. The importance of waist circumference and BMI for mortality risk in diabetic adults. Diabetes Care. 2013 Oct;36(10):3128-30. doi: 10.2337/dc13-0219.

[3] Seo MH, Lee WY, Kim SS, et al. Corrigendum: 2018 Korean Society for the Study of Obesity Guideline for the Management of Obesity in Korea. J Obes Metab Syndr. 2019;28(2):143. doi:10.7570/jomes.2019.28.2.143

[4] Sang Yeoup Lee, Hye Soon Park, Dae Jung Kim, Jee Hye Han, Seon Mee Kim, Guem Joo Cho, Dae Young Kim, Hyuk Sang Kwon, Sung Rae Kim, Chang Beom Lee, Seung Joon Oh, Cheol Young Park, Hyung Joon Yoo. Appropriate waist circumference cutoff points for central obesity in Korean adults Diabetes Research and Clinical Practice, 75:72-80, ISSN 0168-8227 doi:10.1016/j.diabres.2006.04.013, 2007

[5] Obesity prevalence rate, Korea CDC

http://www.index.go.kr/potal/stts/idxMain/selectPoSttsldxMainPrint.do?

idx_cd=2705\&board_cd=INDX_001

[6] P. Kopelman. Health risks associated with overweight and obesity Obesity Reviews: An Official Journal of the International Association for the Study of Obesity, 8 Suppl 1:13-17 doi:10.1111/j.1467789X.2007.00311.x, 2007

[7] Locke AE, Kahali B, Berndt SI, et al. Genetic studies of body mass index yield new insights into obesity biology. Nature. 2015;518(7538):197-206. doi:10.1038/nature14177

[8] Christakis NA, Fowler JH. The spread of obesity in a large social network over 32 years. N Engl J Med. 2007 Jul 26;357(4):370-9. doi: 10.1056/NEJMsa066082. doi: 10.1056/NEJMsa066082

[9] Mia A. Papas, Anthony J. Alberg, Reid Ewing, Kathy J. Helzlsouer, Tiffany L. Gary, Ann C. Klassen, The Built Environment and Obesity, Epidemiologic Reviews, Volume 29, Issue 1, 2007, Pages 129-143, https://doi.org/10.1093/epirev/mxm009

[10] Tae-Won Jang, Hyoung-Ryoul Kim, Hye-Eun Lee, Jun-Pyo Myong, Jung-Wan Koo, Long Work Hours and Obesity in Korean Adult Workers, Journal of Occupational Health, Article ID 13-0043-OA, [Advance publication] Released July 26, 2013, Online ISSN 1348-9585, Print ISSN 1341-9145, https://doi.org/10.1539/joh.13-0043-OA

[11] Ko, G., Chan, J., Chan, A. et al. Association between sleeping hours, working hours and obesity in Hong Kong Chinese: the 'better health for better Hong Kong' health promotion campaign. Int J Obes 31, 254-260 (2007). https://doi.org/10.1038/sj.ijo.0803389

[12] Gu JK, Charles LE, Bang KM, et al. Prevalence of obesity by occupation among US workers: the National Health Interview Survey 2004-2011. J Occup Environ Med. 2014;56(5):516-528.

doi:10.1097/JOM.0000000000000133 
[13] Allman-Farinelli MA, Chey T, Merom D, Bauman AE. Occupational risk of overweight and obesity: an analysis of the Australian Health Survey. J Occup Med Toxicol. 2010;5:14. Published 2010 Jun 16. doi:10.1186/1745-6673-5-14

[14] Peplonska B, Bukowska A, Sobala W. Association of Rotating Night Shift Work with BMI and Abdominal Obesity among Nurses and Midwives. PLoS One. 2015;10(7):e0133761. Published $2015 \mathrm{Jul}$ 21. doi:10.1371/journal.pone.0133761

[15] Kim, M., Son, K., Park, H. et al. Association between shift work and obesity among female nurses: Korean Nurses' Survey. BMC Public Health 13, 1204 (2013). https://doi.org/10.1186/1471-2458-13-1204

[16] Lee JY et al., Trends in Obesity Prevalence by Occupation Based on Korean National Health and Nutrition Examination Survey From 1998 to 2015, Safety and Health at Work, https://doi.org/10.1016/j.shaw.2019.08.003

[17] Nam JY, Kim J, Cho KH, et al. Associations of sitting time and occupation with metabolic syndrome in South Korean adults: a cross-sectional study. BMC Public Health. 2016;16(1):943. Published 2016 Sep 7. doi:10.1186/s12889-016-3617-5

[18] Her, E.-S. (2019). Nutrients Intake and Health Indices by Occupation in Middle-Aged Men - Using the Korean National Health and Nutrition Examination Survey (KNHANES) 2013-2016 - The Korean Journal of Food and Nutrition 2019, vol.32, no.3, pp. 216-225 (10 pages) DOI : 10.9799/ksfan.2019.32.3.216

[19] Ma WY, Yang CY, Shih SR, et al. Measurement of Waist Circumference: midabdominal or iliac crest? Diabetes Care. 2013;36(6):1660-1666. doi:10.2337/dc12-1452

[20] Ishizaki M, Yamada Y, Morikawa Y, et al. The relationship between waist-to-hip ratio and occupational status and life-style factors among middle-aged male and female Japanese workers. Occup Med (Lond). 1999;49(3):177-182. doi:10.1093/occmed/49.3.177

[21] Shimokawa S, Chang HH, Pinstrup-Andersen P. Understanding the differences in obesity among working adults between Taiwan and China. Asia Pac J Clin Nutr. 2009;18(1):88-95. PMID: 19329401.

[22] Siddiquee, T., Bhowmik, B., Da Vale Moreira, N.C. et al. Prevalence of obesity in a rural Asian Indian (Bangladeshi) population and its determinants. BMC Public Health 15, 860 (2015). https://doi.org/10.1186/s12889-015-2193-4

[23] Luckhaupt SE, Cohen MA, Li J, Calvert GM. Prevalence of obesity among U.S. workers and associations with occupational factors. Am J Prev Med. 2014 Mar;46(3):237-48. doi:

10.1016/j.amepre.2013.11.002. PMID: 24512862.

[24] Lahti-Koski M, Vartiainen E, Männistö S, Pietinen P. Age, education and occupation as determinants of trends in body mass index in Finland from 1982 to 1997. Int J Obes Relat Metab Disord. 2000 Dec;24(12):1669-76. doi: 10.1038/sj.ijo.0801437. PMID: 11126222. 
[25] Proper KI, Hildebrandt VH. Overweight and obesity among Dutch workers: differences between occupational groups and sectors. Int Arch Occup Environ Health. 2010 Jan;83(1):61-8. doi: $10.1007 / \mathrm{s} 00420-009-0438-1$

[26] Berglund E, Lytsy P, Westerling R. Active Traveling and Its Associations with Self-Rated Health, BMI and Physical Activity: A Comparative Study in the Adult Swedish Population. Int J Environ Res Public Health. 2016;13(5):455. Published 2016 Apr 28. doi:10.3390/ijerph13050455

[27] Mitu, B. and Youngjin Choi. "CONFUCIANISM AND THE CONTEMPORARY KOREAN SOCIETY." (2015).

[28] Park, Chong-Min, and Doh Chull Shin. "Do Asian Values Deter Popular Support for Democracy in South Korea?" Asian Survey, vol. 46, no. 3, 2006, pp. 341-361. JSTOR, www.jstor.org/stable/10.1525/as.2006.46.3.341

[29] Sleziak, Tomasz. (2013). The Role of Confucianism in Contemporary South Korean Society. Annual of Oriental Studies - Rocznik Orientalistyczny. LXVI. 27-46.

[30] Steeves, Jeremy \& Bassett, David \& Thompson, D.L. \& Fitzhugh, Eugene. (2011). Relationships of occupational and non-occupational physical activity to abdominal obesity. International journal of obesity (2005). 36. 100-6. doi:10.1038/ijo.2011.50.

[31] Addo, P.N.O., Nyarko, K.M., Sackey, S.O. et al. Prevalence of obesity and overweight and associated factors among financial institution workers in Accra Metropolis, Ghana: a cross sectional study. BMC Res Notes 8, 599 (2015). https://doi.org/10.1186/s13104-015-1590-1

[32] Bruna Galobardes, Alfredo Morabia, Martine S Bernstein, Diet and socioeconomic position: does the use of different indicators matter?, International Journal of Epidemiology, Volume 30, Issue 2, April 2001, Pages 334-340, https://doi.org/10.1093/ije/30.2.334

[33] Lachat C, Nago E, Verstraeten R, Roberfroid D, Van Camp J, Kolsteren P. Eating out of home and its association with dietary intake: a systematic review of the evidence. Obesity reviews: an official journal of the International Association for the Study of Obesity. 2012;13(4):329-346. doi:10.1111/j.1467789X.2011.00953.x.

[34] Singer RH, Stoutenberg M, Gellman MD, Archer E, Davis SM, et al. (2016) Occupational Physical Activity and Body Mass Index: Results from the Hispanic Community Health Study / Study of Latinos. PLOS ONE 11(3): e0152339. https://doi.org/10.1371/journal.pone.0152339

\section{Tables}


Table 1. Demographic characteristics of subjects

\begin{tabular}{|c|c|c|c|}
\hline \multirow[t]{2}{*}{ Variables } & \multicolumn{3}{|c|}{$\underset{\substack{\text { Total } \\
(n=3645)}}{-}$} \\
\hline & Male(n=1862) & Female(n=1783) & P-value \\
\hline Age & & & $<0.001$ \\
\hline $20-29$ & $177(9.5)$ & $235(13.2)$ & \\
\hline $30-39$ & $366(19.7)$ & $285(16.0)$ & \\
\hline $40-49$ & $418(22.4)$ & $424(23.8)$ & \\
\hline $50-59$ & $431(23.1)$ & $445(25.0)$ & \\
\hline $60-64$ & $202(10.8)$ & $153(8.6)$ & \\
\hline $65+$ & $268(14.4)$ & $241(13.5)$ & \\
\hline Occupation category & & & $<0.001$ \\
\hline Managers & $66(3.5)$ & $7(0.4)$ & \\
\hline Professionals and related workers & $387(20.8)$ & $430(24.1)$ & \\
\hline Clerks & $300(16.1)$ & $307(17.2)$ & \\
\hline Service workers & $123(6.6)$ & $341(19.1)$ & \\
\hline Sales workers & $155(8.3)$ & $207(11.6)$ & \\
\hline Skilled agricultural, forestry and fishery workers & $145(7.8)$ & $79(4.4)$ & \\
\hline Craft and related trades workers & $230(12.4)$ & $49(2.7)$ & \\
\hline $\begin{array}{l}\text { Equipment, machine operating and } \\
\text { assembling workers }\end{array}$ & $275(14.8)$ & $49(2.7)$ & \\
\hline Elementary workers & $181(9.7)$ & $314(17.6)$ & \\
\hline Education & & & $<0.001$ \\
\hline Elementary school or lower & $187(10.0)$ & $279(15.6)$ & \\
\hline Middle school & $158(8.5)$ & $172(9.6)$ & \\
\hline High school & $637(34.2)$ & $591(33.1)$ & \\
\hline College or higher & $880(47.3)$ & $741(41.6)$ & \\
\hline Income & & & 0.342 \\
\hline Low & $388(20.8)$ & $384(21.5)$ & \\
\hline Mid-low & $497(26.7)$ & $443(24.8)$ & \\
\hline Mid-high & $496(26.6)$ & $457(25.6)$ & \\
\hline High & $481(25.8)$ & $499(28.0)$ & \\
\hline Alcohol(1 year) & & & $<0.001$ \\
\hline Never in a year & $195(10.5)$ & $295(16.5)$ & \\
\hline Below once a month & $234(12.6)$ & $455(25.5)$ & \\
\hline Once a month & $145(7.8)$ & $190(10.7)$ & \\
\hline 2-4 per month & $515(27.7)$ & $406(22.8)$ & \\
\hline 2-3 per week & $477(25.6)$ & $216(12.1)$ & \\
\hline More than 4 per week & $248(13.3)$ & $52(2.9)$ & \\
\hline Never & $48(2.6)$ & $169(9.5)$ & \\
\hline Smoking & & & $<0.001$ \\
\hline Everyday & $611(32.8)$ & $83(4.7)$ & \\
\hline Sometimes & $87(4.7)$ & $32(1.8)$ & \\
\hline Ex-smoker & $752(40.4)$ & $113(6.3)$ & \\
\hline Never & $412(22.1)$ & $1555(87.2)$ & \\
\hline
\end{tabular}




\begin{tabular}{|c|c|c|c|c|c|c|c|c|c|c|}
\hline & \multicolumn{5}{|c|}{$\begin{array}{l}\text { Male } \\
n=1862\end{array}$} & \multicolumn{5}{|c|}{$\begin{array}{l}\text { Female } \\
n=1783\end{array}$} \\
\hline & total & BMI & p-value & wc & p-value & total & BMI & p-value & wc & p-value \\
\hline Occupation category & & $24.8 \pm 3.3$ & 0.002 & $87.0 \pm 9.7$ & 0.001 & & $23.3 \pm 3.6$ & 0.002 & $77.8 \pm 9.4$ & 0.001 \\
\hline Managers & 66 & $25.7 \pm 2.6$ & & $90.0 \pm 7.2$ & & 7 & $21.9 \pm 2.5$ & & $75.9 \pm 7.3$ & \\
\hline Professionals and related workers & 387 & $25.0 \pm 3.2$ & & $87.3 \pm 8.2$ & & 430 & $22.5 \pm 3.3$ & & $74.7 \pm 8.4$ & \\
\hline Clerks & 300 & $24.9 \pm 3.2$ & & $87.1 \pm 8.3$ & & 307 & $22.4 \pm 3.5$ & & $74.6 \pm 8.9$ & \\
\hline Service workers & 123 & $24.7 \pm 3.3$ & & $86.1 \pm 9.3$ & & 341 & $24.0 \pm 3.6$ & & $79.5 \pm 9.3$ & \\
\hline Sales workers & 155 & $25.2 \pm 3.5$ & & $88.8 \pm 9.4$ & & 207 & $23.4 \pm 3.5$ & & $78.0 \pm 82.4$ & \\
\hline Skilled agricultural, forestry and fishery workers & 145 & $24.4 \pm 3.2$ & & $87.5 \pm 9.6$ & & 79 & $25.0 \pm 3.7$ & & $82.4 \pm 10.1$ & \\
\hline Craft and related trades workers & 230 & $24.3 \pm 3.3$ & & $85.2 \pm 8.4$ & & 49 & $23.9 \pm 3.6$ & & $78.6 \pm 9.0$ & \\
\hline $\begin{array}{l}\text { Equipment, machine operating and } \\
\text { assembling workers }\end{array}$ & 275 & $24.9 \pm 3.4$ & & $87.0 \pm 9.4$ & & 49 & $23.7 \pm 3.3$ & & $78.5 \pm 9.1$ & \\
\hline Elementary workers & 181 & $24.2 \pm 3.3$ & & $86.4 \pm 8.2$ & & 314 & $24.2 \pm 3.5$ & & $81.7 \pm 9.1$ & \\
\hline
\end{tabular}

Table3. The p-value of ANCOVA analysis between obesity markers and occupations

\begin{tabular}{|c|c|c|}
\hline \multirow[t]{2}{*}{ Measure } & \multicolumn{2}{|c|}{ Occupation } \\
\hline & Male & Female \\
\hline BMI & 0.042 & 0.214 \\
\hline WC & 0.002 & 0.293 \\
\hline
\end{tabular}

\section{Figures}




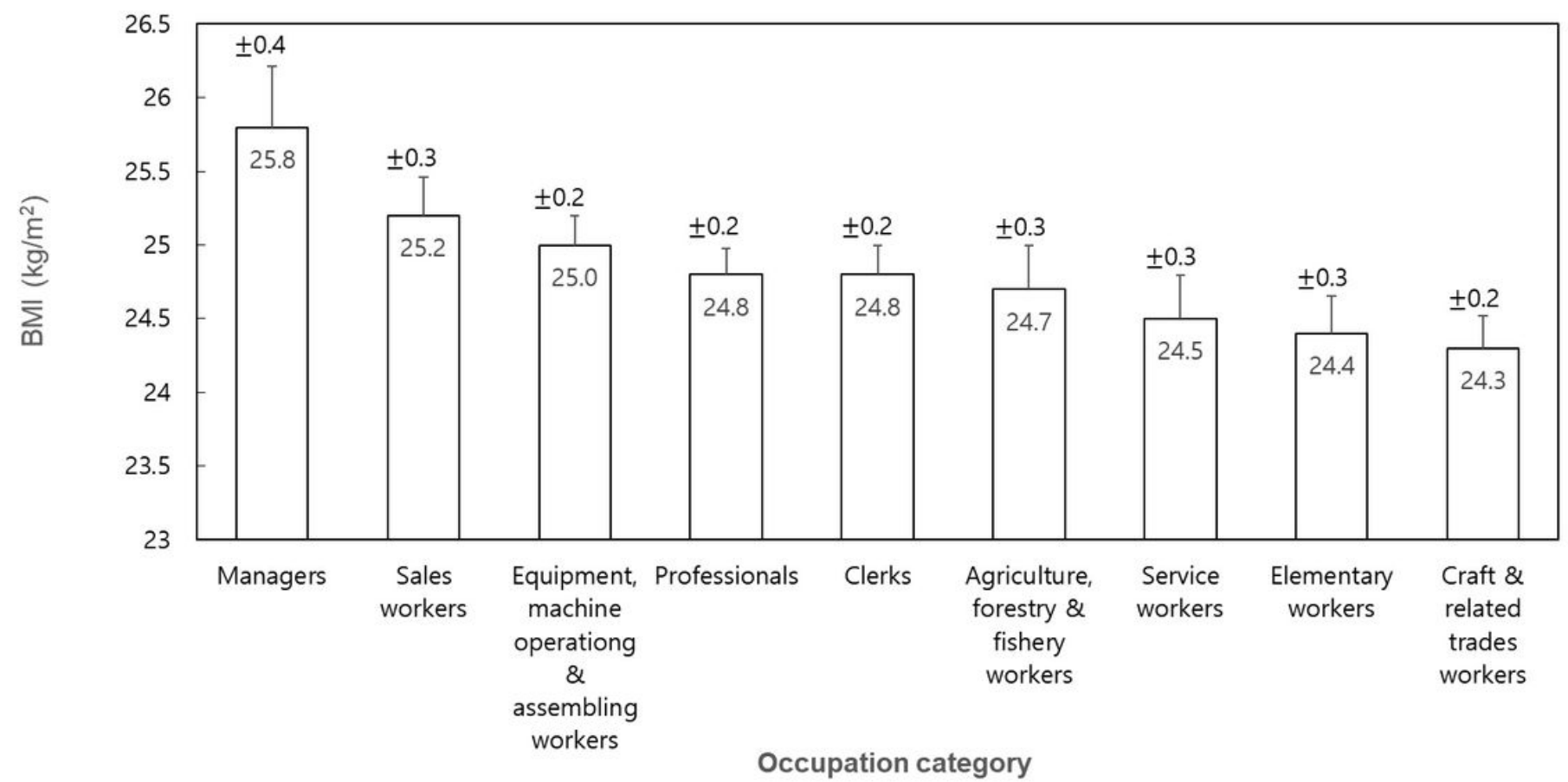

Figure 1

The BMI and WC (Mean \pm S.D.) estimates were based on the occupational categories using post hoc analysis

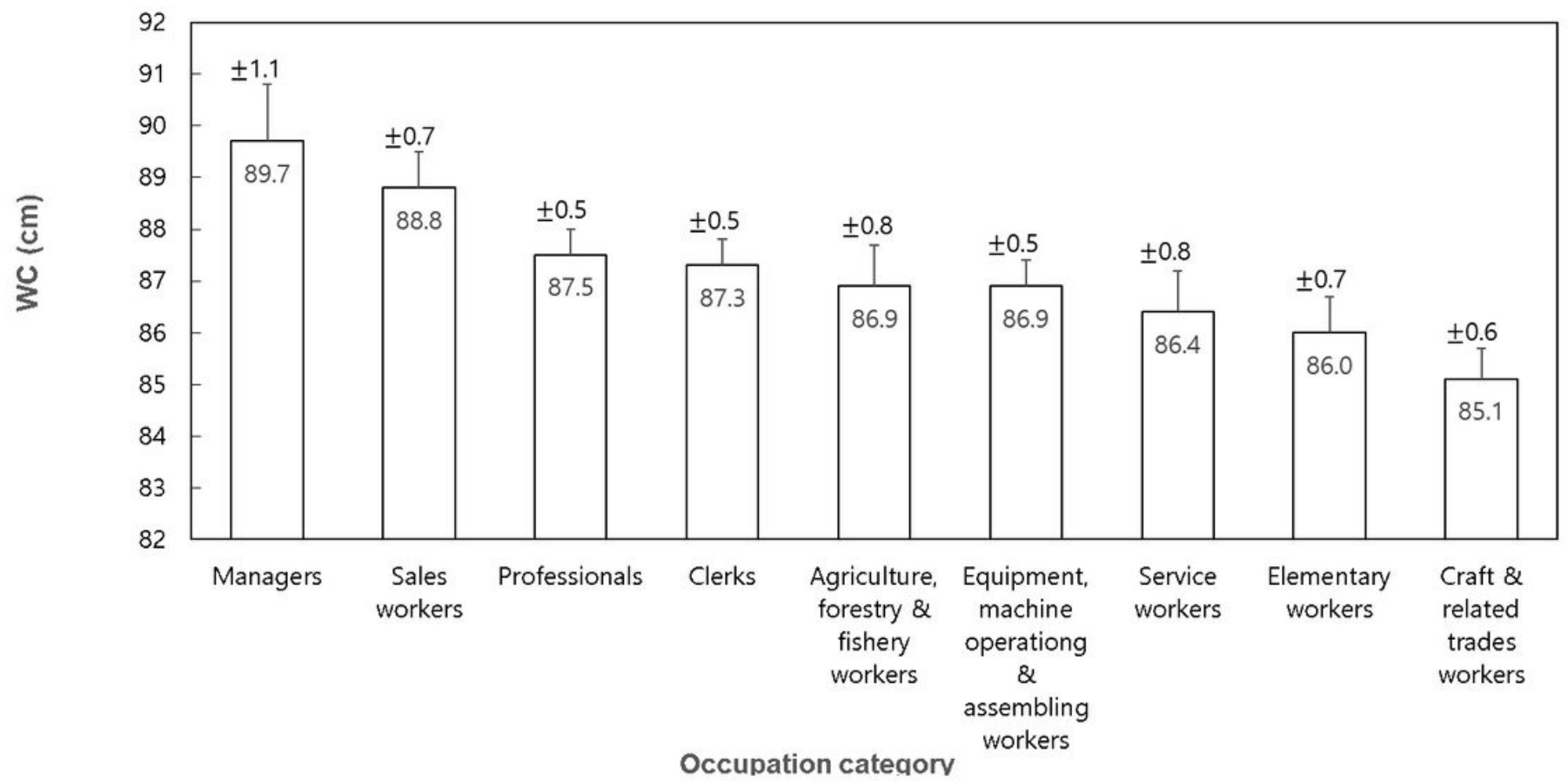


Figure 2

The BMI and WC (Mean \pm S.D.) estimates were based on the occupational categories using post hoc analysis 